NBER WORKING PAPER SERIES

MEASURING THE EFFECT OF

AN ANTIDISCRIMINATION PROGRAM

Orley Ashenfelter*

James Heckman*

Working Paper No. 50

CENTER FOR ECONOMIC ANALYSIS OF HUMAN BEHAVIOR AND SOCIAL INSTITUTIONS

National Bureau of Economic Research. Inc.

204 Junipero Serra Boulevard, Stanford, California 94305

August, 1974

Preliminary; Not for Quotation

NBER working papers are distributed informally and in 1imited number for comments only. They should not be quoted without written permission.

This report has not undergone the review accorded officlal NBER nublications; in particular, it has not yet been submitted for approval by the Board of Directors.

This research was supported by an Equal Employment Opportunity Commission grant to the Metropolitan Applied Research Council, New York, New York. Heckman's research was partially supported by U.S. Labor Department grant No. L73-135 to the NBER. We wish to thank Sherwin Rosen for perceptive comments made on an earlier version of this paper. Ralph Shnelvar performed the calculations.

*Orley Ashenfelter, Princeton University

James Heckman, The University of Chicago and NBER 
MEASURING THE EFFECT OF AN ANTIDISCRIMINATION PROGRAM

Orley Ashenfelter

James Heckman

July 1974

The authors are, respectively, Professor, Department of Economics, Princeton University, and Associate Professor, Department of Economics, The University of Chicago and Research Associate, National Bureau of Economic Research.

This research was sponsored by an Equal Employment Opportunity Commission grant to the Metropolitan Applied Research Council, New York, New York. Heckman's research was partially supported by a U.S. Labor Department grant to the National Bureau of Economic Research. We wish to thank Sherwin Rosen for perceptive comments made on an earlier version of this paper. Ralph Shnelvar performed the calculations. 
Since 1941, six Executive Orders have been issued forbidding Federal government contractors from discriminating against minority workers. ${ }^{1}$ The latest and strongest Order, 11246, issued in 1965, enjoins firms to take affirmative action in recruiting and promoting minority workers. Contractor firms are required to abide by the order in all operations including those unrelated to the performance of the contract. In principle, all prospective contractors are required to demonstrate compliance with the law before a contract is let. The potential penalties are severe: failure to comply with the law may result in revocation of current contracts and suspension of the right to bid on future contracts.

Despite these provisions, doubts have been raised about the effectiveness of the Orders. In part, these doubts are based on the small size of the enforcement staff relative to the population of potential violators. ${ }^{2}$ The division of responsibility between the office of Federal Contract Compliance (OFCC) and the staffs of the various Federal departments weakens the enforcement effort. The order is imprecise as to the definition of "discrimination" and "affirmative action." To heighten doubts, before 1971 no firm had its contract revoked for noncompliance.

Defenders of the Orders cite cases in which contract award dates have been postponed until firms have taken steps toward compliance with the law. Competition among contractors has led firms to adopt affirmative action programs to improve their chances of winning contracts.

In this paper, we investigate these competing claims using data from 40,445 establishments sampled in 1966 and 1970. For this period, 
we find that the employment of black males relative to white males increased 3.3 percent more in firms with government contracts than in firms without contracts. This comparison controls for the effect of employment expansion, variation in the size of firms, and geographical variation in the supply of labor. Using similar controls, we find little evidence to support the view that the Orders have improved the relative occupational distribution of black workers. We find strong evidence that among segregated firms, contractors are more likely to integrate than noncontractors.

In the first section of this paper, we distinguish what can be measured from what cannot. We develop a framework to measure and interpret program effects. In the second section we discuss the design of our sample and present results of an analysis of the randomness of this sample. In the third and concluding section, we present the estimates and discuss their plausibility. 


\section{A Framework of Analysis}

\section{a. What Is and Is Not Measured}

In this study, we attempt to measure the effect of Executive Order 11246 on the employment and occupational distribution of black males relative to white males in Federal contractor firms compared to identical relative measures for blacks in noncontractor firms. Before discussing specific indices, it is clarifying to consider a problem that plagues this, and other studies that seek to measure the effect of a program on its target population. ${ }^{3}$ Since we have a (two point) time series, a natural method for assessing the effectiveness of a program is to measure the change in a suitable index for target firms relative to the change in the index for the remaining firms. The basic problem is the absence of a control group in the presence of a program with economy-wide impact. Although a program may directly affect one group of firms, it also indirectly affects the remaining group of firms as we11. Accordingly, comparisons of changes in the relative status of blacks in target and nontarget firms cannot be measured relative to what might have been in the absence of the program since that state is not observed. Thus, we cannot measure the contribution of the Executive Order to improvements in the aggregate relative status of blacks. Nonetheless, we can measure whether or not the contract compliance program has had any differential impact on the two types of firms.

Consider an index of black male relative (to white male) status measured at time $t, s_{t}$. This index will be defined more precisely 
below, but for the purposes of the present discussion, it can be viewed as an acceptable index of relative black male welfare. The proportionate change in this index through time

(1) $\quad I=\frac{s_{t}-s_{t-1}}{s_{t-1}}$

affords a measure of trend in black economic status. The actual behavior of $\mathrm{S}_{t}$ is to be distinguished from the hypothetical behavior $s_{t}^{h}$ that would have occurred in the absence of the program. Proportionate movements in the hypothetical index

(2) $\quad I_{h}=\frac{s_{t}^{h}-s_{t-1}^{h}}{s_{t-1}^{h}}$

measure trends in relative black economic welfare in the absence of the program.

Index I can be fruitfully decomposed into three components. Denoting the relative status of blacks in contractor firms at time $t$ by $\mathrm{S}_{t}^{\mathrm{g}}$, one measure of the change in relative black status in contractor firms compared to the hypothetical change in the absence of a contract is

$$
I_{g}=\frac{s_{t}^{g}}{s_{t-1}^{g}}-\frac{s_{t}^{h}}{s_{t-1}^{h}} .
$$

Assuming small changes, we may write

$$
\ln \left(1+I_{g}\right) \stackrel{\sim}{=} I_{g}=\Delta \ln s_{t}^{g}-\Delta \ln s_{t}^{h} .
$$


Using obvious notation, a similar index for blacks in noncontractor firms may be written

$$
\ln \left(1+I_{n g}\right) \cong I_{n g}=\Delta \ln s_{t}^{n g}-\Delta \ln s_{t}^{h}
$$

If fraction $G$ of black employment is in contractor firms, the observed total change in the relative position of blacks may be written as

$$
\Delta \ln S_{t}=\Delta \ln S_{t}^{h}+G\left(\Delta \ln S_{t}^{g}-\Delta \ln S_{t}^{h}\right)+(1-G)\left(\Delta \ln S_{t}^{n g}-\Delta \ln S_{t}^{h}\right)
$$

$$
=\Delta \ln S_{t}^{h}+G I_{g}+(1-G) I_{n g} \text {. }
$$

Equivalently,

$$
\Delta \ln s_{t}=\Delta \ln s_{t}^{n g}+G\left(\Delta \ln s_{t}^{g}-\Delta \ln s_{t}^{n g}\right)
$$

Note that $I_{n g}$ and $I_{g}$ are meaningful only if black status would be the same in both contractor and noncontractor firms in the absence of a compliance program.

The first component of equation (6) is the change that would occur in the absence of the program. We cannot measure this component, nor can we measure $I_{G}$ or $I_{n g}$. We can measure the components of equation (7). The first component of this equation is the change in relative black status in noncontractor firms. The second component measures the difference in the change in black status between contractor and noncontractor firms weighted by the proportion of black employment in contractor firms. 
If contracts were randomly assigned to firms, a simple calculation of mean changes in contractor and noncontractor firms would allow us to estimate the two components of total change in equation (7). Since random selection is unlikely, an alternative approach which is pursued in this paper is to utilize regression techniques to standardize for nonrandom changes in the indices for the two types of firms. We postulate the following relationship for firm $\mathrm{k}$ :

$$
\Delta \ln S_{t k}=B X_{t k}+\gamma d_{k}+\varepsilon_{t k}
$$

where $d_{k}$ is a dummy variable with a value of unity for firms holding a government contract in the second period of the data, $x_{t k}$ is a vector of control variables, and $\varepsilon_{t k}$ is a disturbance with the classical properties. Estimates of " $\gamma$ ", weighted by G, yield an estimate of the second component of equation (7).

The available data put substantial restrictions on the way in which the quantity $\mathrm{S}$ may be measured. Since we do not have wage data, we must use more approximate measures of black relative economic status. First, consider the index of occupational position for black workers whose logarithm is defined by

$$
\ln O_{b}=\sum\left(B_{j} / B\right) \ln P_{j},
$$

where $B_{j} / B$ is the fraction of all black workers in the $j$ th occupation and $\ln \mathrm{P}_{j}$ is the logarithm of the mean salary of all workers in the jth occupation. $o_{b}$ is nothing more than the (geometric) mean salary 
that would be received by black workers if they were paid the average wage a white worker within the occupation is paid. $o_{b}$ therefore reflects only variation in the occupational distribution of black workers and is nothing more than a method for summarizing the information available on that distribution. If we define $\mathrm{O}_{\mathrm{W}}$ as the occupational distribution index for white workers, one possible measure of the quantity $S$ is the ratio $0_{b} / 0_{w}$. The disadvantage in using this measure is that it does not reflect the relative number of black workers in an establishment. An alternative measure of $S$ is $(B / W)\left(O_{b} / O_{w}\right)$, which corrects for this deficiency. $(\mathrm{B} / \mathrm{W})\left(\mathrm{O}_{\mathrm{b}} / \mathrm{O}_{\mathrm{w}}\right)$ is the ratio of the total compensation of black workers to the total compensation of white workers that would be received if black and white workers were paid the mean salary that is paid to all workers in each occupation. Defining $S=(B / W)\left(O_{b} / 0_{w}\right)$ it follows that $\ln S$ may be decomposed according to

$$
\begin{aligned}
\ln S & =\ln \left(O_{b} / O_{w}\right)+\ln (B / W) \\
& =\left[\Sigma\left(B_{j} / B\right) \ln P_{j}-\Sigma\left(W_{j} / W\right) \ln P_{j}\right]+\ln (B / W) \\
& =\Sigma\left[\left(B_{j} / B\right)-\left(W_{j} / W\right)\right] \ln P_{j}+\ln B / W,
\end{aligned}
$$

so that for $\Delta$ In $S$ we have

$$
\Delta \ln S=\Sigma\left[\Delta \mathrm{B}_{j} / \mathrm{B}-\Delta \mathrm{W}_{j} / \mathrm{W}\right] \ln \mathrm{P}_{j}+\Delta(\ln B-\ln \mathrm{W}) .
$$

Thus, we decompose the relative wage share into components of interest in their own right, and perform a separate regression analysis 
for each component. We estimate a separate coefficient for the dummy "presence of government contract" for each occupation, and for the relative employment equation. Assuming $J$ occupations, and letting $\gamma_{j}$ be the coefficient of the dummy for occupation $j$, and letting $\gamma_{E}$ be the coefficient of the dumm in the relative employment equation,

$$
\sum_{j=1}^{J} \gamma_{j} \ln P_{j}+\gamma_{E}
$$

measures the estimated average difference in the ratio of the payroll of blacks to the payroll of whites between firms with a government contract and those without, holding other factors constant.

If $\gamma_{E}$ is positive and statistically significant, government contracts induce greater relative employment of black males. If $\gamma_{j}$ is positive and significant, the presence of a government contract alters the occupational distribution of black workers relative to white workers towards greater relative concentration of blacks in occupation $j$ in contractor firms. The measured occupational shift may arise for several reasons: internal promotion within existing labor forces, lateral occupational moves between contractor and noncontractor sectors, and nonlateral moves between sectors.

If internal promotion is the only factor at work the expression

$$
I_{J}=\sum_{j=1}^{J} \gamma_{j} \ln P_{j}
$$

measures the differential shift in contractor firms, as compared to noncontractor firms, in the difference between the geometric mean of the 
black male wage distribution and the geometric mean of the white male wage distribution. Thus $I_{J}$ is a measure of differential promotion rates of blacks relative to whites between contractor and noncontractor firms. Reshuffling of workers between contractor and noncontractor sectors obscures this measure. A lateral occupational move of a black from the noncontractor sector to the contractor sector does not contribute to the improvement of the black workforce that existed before the contract was let. Accordingly, on this score we cannot strictly interpret $I_{J}$ as a relative measure of advancement of black workers. Nonetheless, since in a competitive labor market sectoral transfers occur only if wages are raised in contractor firms, a statistically significant $\gamma_{j}$ gives indirect evidence of a rise in black wages relative to white wages in occupation $j$ for contractor firms.

Nonlateral reshuffling between contractor and noncontractor firms has the same unmeasured wage effect. In addition, there is a promotion (or retardation) effect if the transfer of blacks relative to the transfer of whites to contractor firms alters pre-transfer differences between black and white occupational distributions within contractor firms. If the regression equations are properly specified, this source of movement in the index $I_{J}$ measures the effect of occupational advancement (or retardation) through transfer.

of these three sources, only lateral shuffling creates ambiguity in interpretation. Since we cannot measure the magnitude of the changes due to each source, we cannot measure the importance of this component in contributing to the measured total movement of the index. However, if it is small, the index $I_{J}$ weighted by the proportion of 
post program black employment in government contractor firms measures the direct contribution of the contract compliance program to relative black occupationa1 advancement.

\section{b. Specification of the Regression Relationships}

The literature on the employment dynamics of the firm suggests that fixity in factors causes firms to gradually adjust current levels and composition of employment to long-run target levels. We incorporate this idea into the regression equations and make the further assumption of separability between the dynamic system generating firm racial occupational differentials and the equation generating relative employment.

To simplify the notation, we supress subscripts for individual firms. Let $o_{t}$ be a $J \times 1$ vector where the $j$ th row is the difference in the proportions of the black and white forces in occupation $j$ for year $t$, i.e.,

$$
o_{t j}=\frac{B_{t j}}{B_{t}}-\frac{W_{t j}}{W_{t}} \text {. }
$$

A firm's adjustment system may be written as

$$
o_{t}-o_{t-1}=\Lambda\left(0_{t}^{*}-o_{t}\right)
$$

where $\Lambda$ is a $J$ x J matrix of partial adjustment coefficients and 0 is the long-run level of occupational differentials.

This relationship is exact if firm cost functions for movement to equilibrium, and for persistence in disequilibrium are quadratic and 
if the target level, $0_{t}^{*}$, does not depend on the costs of adjustment. Otherwise, the adjustment function may be viewed as an approximation to the true process of adjustment. Allowing $\Lambda$ to be a general matrix, we explicitly incorporate the notion of interrelated adjustment processes introduced into the literature by Nadiri and Rosen. ${ }^{4}$ The $j$ th component of $0_{t}^{*}$ is given by

$$
o_{t j}^{*}=\beta_{j} X+\gamma_{j} d
$$

where, as before, $d$ is one if a firm has a government contract and is zero otherwise. A common set of $\mathrm{K}$ variables, " $\mathrm{X}$ ", is assumed to determine all occupational differentials. With this specification, we may rewrite equation (13) as

$$
o_{t}-o_{t-1}=\Lambda \beta \bar{X}-\Lambda \Gamma d-\Lambda o_{t-1}+\varepsilon_{t}
$$

where $\varepsilon_{t}$ is a $J \times 1$ vector of disturbances, $\bar{x}$ is a matrix with $J$ identical columns of the $\mathrm{K} \times 1 \times$ vector, and $\beta$ is a JxK matrix whose rows are the $\beta_{j}$ vectors for each of the $J$ relationships, $j=1, \ldots, J$. " $\Gamma$ " is a vector whose $j$ th element is the coefficient of the dummy variable for the $j$ th long-run relationship. " $\Lambda \beta$ " and " $\Lambda$ " are the short-run coefficients. Since $o_{t}$ is a column vector of differences in proportions, the sum of the elements of $o_{t}$ must be zero (i.e., if $i$ is a $J \times 1$ vector of unit elements, $i^{\prime} O_{t}=0$ for all $t$ ). This arithmetic relationship induces an exact linear dependency among the $0_{t-1}$ regressors. By omitting one row of $0_{t-1}$, we can avold exact multicollinearity among 
the regressors. Less obviously, we can delete any one of the $J$ equations and estimate both short-run coefficients $(\Lambda \beta$ and $\Lambda \Gamma$ ) and long-run coefficients ( $\beta$ and $\Gamma$ ). ${ }^{5}$

The equation for relative employment is specified in the same fashion. Only one lagged dependent variable is involved, and complications from proportionate dependent variables are avoided. The regression specification becomes

$$
\left(\frac{B}{W}\right)_{t}-\left(\frac{B}{W}\right)_{t-1}=\lambda x \beta_{E}+\lambda \gamma_{E} d-\lambda\left(\frac{B}{W}\right)_{t-1}+u_{t} .
$$

The same control variables are used as those in equation (15). " $u_{t}$ " is a disturbance with the classical properties. "d" is a dumny variable indicating presence of a government contract.

To control for variations in local labor market conditions, regional measures of firm location are included in the $\mathrm{X}$ vector. In addition, firm size variables are introduced to control the effect of variation in technology and the efficiency of management. Measures of firm growth and decline are used to separate the expansionary effect of government contracts, from the compositional effect which is the focus of this study.

In our data, there are many firms with no black workers. This forces us to confine our estimation of equations (15) and (16) to firms with at least one black worker in both sample years, and is an important limitation of our proposed decomposition.

However, we can utilize the remaining data to investigate the effect of government contract compliance programs on firm integration. 
Since the complete absence of blacks is easily detected, it is likely that among a group of firms initially segregated in 1966, more government contractor firms will be integrated in 1970 than noncontractor firms.

By estimating equations which determine the probability of integration in 1970, we test this hypothesis. 


\section{The Data}

Since 1966, all firms with one hundred employees or more, and all firms with a government contract, are required to file a report on the status of their employment by race and sex for each of the nine broad Census occupational categories. These reports are collected by the Equal Employment Opportunity Commission and placed on magnetic tapes (the EEO-1, tapes). From these annual samples, it is possible to utilize firm identification numbers and geographical codes to match establishments in successive years. This paper utilizes a matched sample of 40,445 such establishments which filed reports in. 1966 and 1970.

The basic dilemma in matching EEO-1 reports for two different years for a given economic unit is that as we take greater care to ensure that the two economic units we match are similar in the two years, we are less likely to complete a successful match. There is thus a basic trade-off between accuracy of the match and the size of the sample. On the one hand, we are interested in careful matching so that the characteristics of firms that are difficult to control in a single cross-section can be controlled by examining the changes from one period to another for firms that maintain the same values of the uncontrolled characteristics. On the other hand, some characteristics of virtually all firms change between one period and another, and we do not want to reduce the size of the matched sample because of minor changes that are probably of little relevance to the analysis. 
The most basic characteristics on which it is hypothetically possible to match EEO-1 reports are the employer identification number (EI), assigned by the Social Security Administration, and zip coded address. As it turned out, the 1966 data did not, in fact, contain zip codes, although the 1970 data did. It was thus not possible to use a matching device based on this characteristic.

The procedure we adopted was based on the existence of the appropriate data, although it can be argued on some grounds that it was a good procedure on its own. Our first step was to aggregate the reports for 1966 and 1970 by E.I. number and county. This resulted in the 117,579 reports filed in 1966 being reduced to 98,655 aggregated units, and the 126,686 reports filed in 1970 being reduced to 96,244 aggregated units (hereafter, "aggregates"). Of these two sets of aggregaged units we were able to find 40,445 aggregated units that were common to both years.

The matched sample of aggregated units was thus about forty percent of all units in the two years. In some ways, however, this is an underestimate of the extent of success of the matching process because the successfully matched units tended to be significantly larger than the unmatched units in the two years. Thus, in 1966 the 98,655 aggregated units represented 25.6 million employees and in 1970 the 96,244 aggregated units represented 28.5 million employees. The 40,445 matched units represented approximately 18.6 million employees, however, which is 65 percent of all employees covered. Thus, when the standard of comparison is the extent of employment in the matched units the success of the matching system is somewhat more impressive. 
Sti11, it is of substantial importance to know the reasons for the failure to match more of the aggregated units than the number indicated. First, if there is some systematic factor at work, knowledge concerning it might be helpful in designing a method to secure a more complete match in future work. Second, it is important to understand the consequences of any systematic factor at work so as to be able to analyze its effects on the sample's bias.

The ideal method for examining the causes of mismatching would be to take a random sample of the units that were not matched in each year and determine the cause for a mismatch in each case. From these data it would be possible to estimate the fraction of mismatched cases due to the variety of factors that may cause a mismatch. ${ }^{6}$ In practice this ideal procedure was unavailable because of constraints of both time and resources. Given the importance of the problem, however, it seemed essential to obtain at least some idea of the causes of nonresponse, and so we pursued the problem in the following crude manner. We first chose a single county to examine in more detail using the criterion that it be inexpensive to query the unmatched firms in the county. Mercer County in New Jersey was chosen for this purpose because of its representative nature regarding industry and minority groups.

There were approximately 180 aggregate units in Mercer County subject to analysis in 1966 and 1970. Of these, 103, or 57 percent of the aggregate units were mismatched, which is significantly higher than the 40 percent matched nationwide. Tables 1 and 2 1ist the largest of the unmatched units in 1960 and 1970 respectively, along with their total employment. 
Table 1. Largest unmatched aggregates (1966) in Mercer County.

\begin{tabular}{|c|c|c|c|}
\hline Name of firm & & No. of & employees \\
\hline American Cigar Corporation & & & 399 \\
\hline Kayes Tex Manufacturing Corporation & $\cdot$ & & 221 \\
\hline First Trenton Bank & & & 422 \\
\hline Mercer Hosipital & & & 727 \\
\hline Rider College & & & 331 \\
\hline Capital Transit & & & 212 \\
\hline Yellow Cab Company & & & 125 \\
\hline Princeton Inn Company & $\cdot$ & & 166 \\
\hline Smooth Surface Floor & & & 451 \\
\hline New Jersey Bel1 Telephone Company Trenton & & & 4,617 \\
\hline H. K. Porter & & & 948 \\
\hline H. D. Lee Company, Inc. & & & 183 \\
\hline State New Jersey Department of Health & & & 730 \\
\hline Automatic Retailer & & & 242 \\
\hline American Biltrite Rubber & & & 785 \\
\hline National Sponge Cushion & & & 148 \\
\hline Mathematics & & & 58 \\
\hline Electro Mechantcal Research & & & 145 \\
\hline
\end{tabular}


Table 2. Largest unmatched aggregates (1970) in Mercer County.

\begin{tabular}{|c|c|c|}
\hline Name of firm & $\begin{array}{l}\text { Number of } \\
\text { employees }\end{array}$ & $\begin{array}{l}\text { Government } \\
\text { contract }\end{array}$ \\
\hline American Biltrite Rubber & 579 & Yes \\
\hline Hill Refrigeration & 1,127 & Yes \\
\hline Stauffer Chemical & 196 & No \\
\hline Atlantic Thrift Stores & 361 & No \\
\hline Dow Jones \& Company, Inc. & 344 & No \\
\hline Trenton Office & 421 & Yes \\
\hline Blakely Laundry Company & 174 & No \\
\hline Goodal1 Rubber Company & 786 & Yes \\
\hline Needham's Motor Service, Inc. & 177 & Yes \\
\hline AAA Trucking Company & 209 & No \\
\hline Oxzyn Company & 370 & No \\
\hline Princeton Applied Research Corporation & 202 & Yes \\
\hline Applied Logic Corporation & 167 & Yes \\
\hline National Sponge Cushion & 166 & No \\
\hline Coca Colla & 111 & Yes \\
\hline Shoprite & 139 & No \\
\hline F:M.C. Chemical Corporation & 391 & Yes \\
\hline DeLeval Holroyd & 149 & Yes \\
\hline Ginos of New Jersey & 119 & No \\
\hline
\end{tabular}


We contacted some of the larger firms on each list to see if we could determine why they had not been matched. As it turned out, the causes could be grouped under three categories: (a) natural causes, (b) errors, and (c) identification problems.

The three major natural factors causing an inability to match were: closing or opening of a new establishment, a decline or increase in size between the two years so that the obligation to file an EEO-1 form changed, and mergers. For example, Princeton Inn with 166 employees in 1966 closed its doors between 1966 and 1970, so that it did not appear in the data for 1970; Yellow Cab Co. with 125 employees in 1966 declined in size to fewer than 100 employees in 1970 so that it no longer had an obligation to file in 1970. Likewise, Gino's of New Jersey with 119 employees in 1970 had grown to over 100 employees between 1966 and 1970 so that it had an ob1igation to file in 1970 but not in 1966. Fina11y, First Trenton Bank with 422 employees in 1966 merged with another bank between 1966 and 1970 so that it no longer existed as a separate entity. Clear1y, each of these cases represents a situation where the normal growth, decline, and consolidation of firms results in some firms appearing in one year but not in another. Aside from changes in reporting requirements, not much could have been done to match records for firms affected by these factors.

Errors in reporting also accounted for some of the failure to match firms. In some cases errors were due to the firms themselves, in other cases the errors were a result of changes in reporting systems from one year to another, and in still other cases it is not possible to determine the source of the error. For example, Mercer Hospital 
has apparently reported every year except 1970 when its EE0-1 form was never filed due to a new computerized data processing system that was installed that year and did not function correctly. The most disturbing unmatched item in Tables 1 and 2 is surely New Jersey Bell Telephone Co. - Trenton, with 4,617 employees in 1966. This unmatched item is apparently due to a limitation in the matching program that resulted from the fact that the Bell System reported on a statewide basis in 1966, but on a county basis in 1970. It was thus not possible to match the same units in the two years. Only those reporting units using a consistent system from year to year would be susceptible of a match using the scheme outlined above. Finally, Dow Jones Co. and New Jersey Department of Health, Trenton, apparently reported in both years with the same name and EI number, although their 1970 reports did not appear on our data tapes. We can only conclude that these reports were either lost or miscoded at some point.

A final cause of mismatching was the problem of identifying firms with a unique EI number. The Social Security Administration, which is responsible for administering the EI numbering system, has assigned 10,000 to 12,000 more EI numbers than there are firms. Thus, a single firm may have more than one EI number and may report using different EI numbers in different years. It is for precisely this reason that American Biltrite Rubber and National Sponge Cushion appear in both Tables 1 and 2 , even though we report them as being unmatched. Each of these companies has more than one EI number and each reported under different EI numbers in the two years 1966 and 1970 . Since the EI number is one of the criteria for matching, this made 1 impossible to match these particular firms. 
Such a limited sampling is not adequate, of course, for making detailed estimates of the proportion of our unmatched firms that are accounted for by natural causes as against the proportion that are accounted for by errors and identification problems. From our limited experience, however, we would guess that perhaps 30 to 60 percent of the unmatched aggregate units are due to errors or improper identification, while the remainder are due to the natural changes in estab1ishments over any four-year period.

In order to explore more systematically the results of the matching process we computed the multiple regression listed in Table 3 . The purpose of this regression is to provide a systematic summary of the differences in the industrial, regional and other characteristics of aggregates as between those that were and were not matched. We pooled a11 of the 96,244 aggregates for 1966 and 1970 and created a dumm dependent variable that took on the value unity if the aggregate fell in the matched sample of firms and zero if it did not. The independent variables are sets of industrial, regional, and other dummy variables. The industrial variables are the set of nine listed in Table 3 plus a deleted variable for agriculture, fisheries, and forestry. The regression coefficients are thus interpreted as the difference between the industry listed in the table and the deleted industry in the probability that an aggregate from that industry was matched, holding the other characteristics in the table constant. For example, Table 3 indicates that holding other things constant, an aggregate in durable manufacturing was .403 more likely to be matched than an aggregate in agriculture. Likewise, an aggregate in durable 
Table 3. Estimates of the effect of various factors on the probability that an aggregate was matched (dependent variable $=1$ if matched, 0 otherwise). 96,244 aggregates for 1966 and 1970.

\begin{tabular}{|c|c|c|c|}
\hline Industry & $\begin{array}{l}\text { Mean of inde- } \\
\text { pendent variable }\end{array}$ & $\begin{array}{l}\text { Regression } \\
\text { coefficient }\end{array}$ & $\begin{array}{l}\text { Absolute } \\
\text { T-value }\end{array}$ \\
\hline 1. Mining & .049 & .306 & 21.1 \\
\hline 2. Durable manufacturing & .187 & .403 & 30.5 \\
\hline 3. Nondurable manufacturing & .191 & .341 & 25.8 \\
\hline \\
\hline $\begin{array}{l}\text { 5. Transportation, communi- } \\
\text { cation, other public } \\
\text { utilities }\end{array}$ & .240 & .272 & 20.5 \\
\hline 6. Wholesale and retail trade & .091 & .336 & 24.2 \\
\hline $\begin{array}{l}\text { 7. Finance, insurance, } \\
\text { real estate }\end{array}$ & .058 & .227 & 15.8 \\
\hline \multicolumn{2}{|l|}{$\begin{array}{l}\text { 8. Business and other } \\
\text { services, entertainment }\end{array}$} & .298 & 21.5 \\
\hline 9. Public administration & .014 & .125 & 2.95 \\
\hline \multicolumn{4}{|c|}{$\begin{array}{l}\text { Region (by first digit of } \\
\text { zip code; see key below) }\end{array}$} \\
\hline 0 & .095 & .041 & 5.84 \\
\hline 1 & .141 & .063 & 9.65 \\
\hline 2 & .098 & -.031 & 4.48 \\
\hline 3 & .102 & .081 & 11.8 \\
\hline 4 & .138 & .063 & 9.64 \\
\hline 6 & .098 & .032 & 4.58 \\
\hline 7 & .092 & .082 & 11.6 \\
\hline 8 & .034 & .078 & 8.15 \\
\hline 9 & .110 & .047 & 6.94 \\
\hline Inside SMSA & .732 & .049 & 13.7 \\
\hline Government contract & .425 & .065 & 20.7 \\
\hline Firm size under 100 employees & .422 & -.205 & 61.1 \\
\hline Firm size over 500 employees & .117 & .170 & 34.1 \\
\hline Intercept & & .061 & \\
\hline
\end{tabular}


Table 3 (concluded)

\section{Key to regions}

0 Puerto Rico, Vermont, New Hampshire, Maine, Massachusetts, Virgin Islands, New Jersey, Connecticut, Rhode Island

1 Pennsylvania, New York, Delaware

2 North Carolina, Virginia, West Virginia, South Carolina, Maryland, District of Columbia

3 Florida, Georgia, Tennessee, Alabama, Mississippi

4 Kentucky, Michigan, Indiana, Ohio

5 Montana, South Dakota, Wisconsin, Minnesota, Iowa, North Dakota

6 Nebraska, Illinois, Kansas, Missouri

7 Texas, Louisiana, Arkansas, Oklahoma

8 Arizona, Colorado, Utah, Wyoming, Idaho, New Mexico, Nevada

9 California, Alaska, Washington, Hawaii, Oregon

\section{Key to industries}

0 Agriculture, forestries, fisheries

$1 \quad$ Mining

2 Durable manufacturing

3 Non-durable manufacturing

4 Chemicals and allied products

5 Transportation, communication and other public utilities

6 Wholesale and retail trade

7 Finance, insurance and real estate

8 Business and repair service, personal services, entertainment and recreation

9 Public administration 
manufacturing was $.062(=.403-.341)$ more likely of being matched than an aggregate in nondurable manufacturing. ${ }^{7}$ There are also ten regional variables, with the fifth deleted. The precise lists of states in each region are presented in the key following Table 3 and is based on the first digit of the zip codes for the aggregates. As before, a regression coefficient is interpreted as the estimated difference between the region examined and the deleted region in the probability that an aggregate was matched, holding other things constant. The remaining variables are dummy variables for whether the firm was inside an SMSA, for whether it had a government contract, and for its size class.

As can be seen from Table 3, the most important determinant of whether an aggregate was matched seems to be its size. Firms with fewer than 100 employees were .21 less 1ikely to be matched than firms with 100 to 500 employees. Likewise, firms with over 500 employees were .17 more likely to be matched than firms with 100 to 500 employees. This result is probably not very surprising given that employer size is an important determinant of whether a firm must report in any year. It suggests that the natural growth and decline of the smaller firms may be an important determinant of the extent of success of the matching process, a result previously discussed. Firms inside SMSA's are also more likely to be matched than firms outside SMSA's, but the size of this effect is not very large. Perhaps more important, firms with government contracts are .065 more likely of being matched than firms without them. It would be interesting to know the extent to which this difference reflects the fact that government contractors have more 
stringent reporting requirements and the extent to which it reflects greater care by government contractors in meeting given reporting requirements. The regional differences do not tend to be very large, and their direction may be surprising to some readers. For one thing, there is no obvious tendency for the matching to be less successful in Southern than in Northern states. Although in simple tabulations there is substantially less matching in the South than the North, this apparently results from the failure to hold constant industry, size of firm, etc. Second, the midwestern states tend to be those where the matching was poorest, although the differences involved are not dramatic. Finally, as we have already noted there are some fairly large differences in the extent of match by industry. Both agriculture and public administration were industry groups where the matching was especially poor, but the finance, insurance, and real estate industry group was a1so notably less successful than other industry groups. The most successful matching was in durable and nondurable manufacturing. Given the few sizable differentials we have noted, however, the remainder of the industry groups do not differ very much in the success of the match.

It is clear from these results that the aggregates in our matched sample are not a random sample of the aggregates we created from the 1966 and 1970 data. If they were, there would be no significant differences between the matched and unmatched samples of firms associated with region, industry, etc. That is, region, industry, and the other variables in Table 3 would not have a significant effect on the probability of a match. In fact, these variables have a statistically significant 
effect. At the same time, it would be easy to exaggerate both the size of the effect that these variables have on the probability of matching and their importance in demonstrating bias. As we have seen, most of the effects of the variables in Table 3 on the probability of a match can be explained by the variable effect of the reporting requirements on whether a firm filed a report in both 1966 and 1970. Thus, the natural consequence of firms growing and declining about the 100 employee reporting requirement is to induce substantial variability in the extent to which some employers file reports in both years, and thus in the probability of a match. On the other hand, the differences in probability of matching by region and industry that we found, and which would be much more difficult to explain by reference to the reporting requirements, are relatively small. In the absence of any further evidence, therefore, it seems very likely that the most important systematic determinant of the non-random character of the matching is the basic reporting requirements. If this is the case, inferences drawn from our matched sample may not be too different from inferences that would have been drawn from the whole population of EEO-1 reports. 


\section{Empirical Results}

\section{a. Estimates of the Components of the Relative Wage Bill}

In this section, we report results from estimating equations (15) and (16). Before presenting the estimates, it is useful to extend the discussion in Section II to consider potential sources of bias that may affect our estimates.

One source is due to improper measurement of the government contract variables. Since the time the first draft of this paper was written, further study has shown that many firms listed as noncontractors in fact were contractors. ${ }^{8}$ Establishments associated with firms doing government contract work in other establishments frequently did not report themselves as contractors. Yet, as noted in the introduction, all plants of a government contractor firm are liable to the provisions of Executive Order 11246. Since geographically disparate units of the same firm are treated as separate data points in our analysis, this source of bias is severe if central managements impose uniform policies in all plants.

However, it is unlikely that uniform policies are applied to a11 establishments. Indeed, it is this presumption which led us to treat separate geographical units as distinct data points. Nonetheless, if government contractors advance blacks at a greater rate than noncontractors, estimates of the government contract effort are biased downwards, and degrees of freedom are overstated to the extent that uniform policies apply to some firms. Given the size of the sample and the number of separate firms, the potential problem with degrees of freedom is unlikely to be important. 
Similarly, potential contractors and recent contractors not listed as contractors in 1970 are expected to be like measured government contractors in all but name. Our inability to identify such firms leads to a downward bias if these firms have taken affirmative action.

There are a host of other biases about which we have much less to say. Since reports are filed by the firm, contractor firms are more likely to exaggerate their compliance effort in order to avoid embarrassing investigations. If this is the case, an upward bias is imparted to our estimates of contract effects. However, it is by no means obvious that this effect applies only to contractor firms. Since noncontractor firms with employment less than one hundred are not required to report, it is likely that the sample of noncontractors includes a biased selection of firms which have taken steps toward affirmative action, or at least are willing to say they have.

Another potential source of bias comes from restricting our sample to establishments with at least one black worker. This restriction is dictated by our choice of the decomposition of the relative wage bill. If contractor firms initially without black workers contribute to decisive gains in the aggregate relative occupational distribution through faster promotion rates, our estimate of the effect of the compliance progress understates the true effect of the program on the mean difference in occupational distributions of blacks and whites between contractor and noncontractor firms. Unfortunately, it is not possible to determine the importance of this effect. Moreover, it is equally possible to imagine that the unmeasured firms are more sluggish in their affirmative action programs than are measured firms. 
Our estimates of equations (15) and (16) are reported in Table 4. The first column reports the relative employment equation. The second column is the (log earnings) weighted sum of the detailed occupational results recorded in columns 3-11. Long-run values, estimated from the scheme of Appendix A, are presented below the standard errors for the estimated coefficients. A convenient summary of these results is reported in Table 5 .

In this table we record both long-run and short-run coefficients for the dummy variables indicating presence of a government contract. Line 1 contains the estimated difference between the percentage change in the employment of black male workers and the percentage change in the employment of white male workers as between firms with and without a government contract, holding other factors constant. According to this estimate, black male employment increased by 3.3 percent more relative to white male employment in firms with government contracts than in firms without them, and this difference is statistically significant. The long-run estimate is 12.9 percent. Lines 2 through 10 contain the percentage point differences between firms with and without government contracts in the change in the percentage of black workers minus the percentage of white workers in each of the nine occupational categories available in the EEO-1 reporting system data. By definition these nine percentage point changes must sum to zero, since an increase in the percentage of black (or white) workers in one occupation implies a decrease in the percentage of black (or white) workers in some other occupation. In effect, the estimated coefficients in 1ines 2-10 of column 2 of Table 5 tell us how the incremental employment of black 


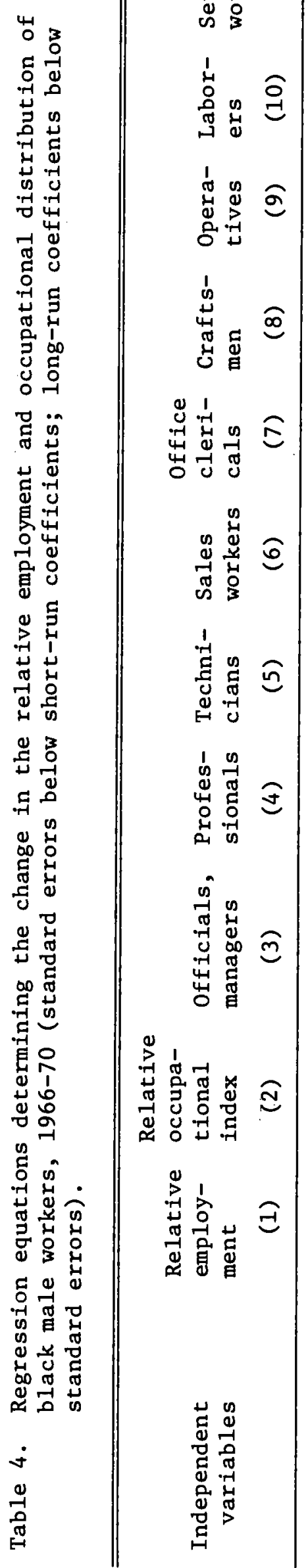

i்

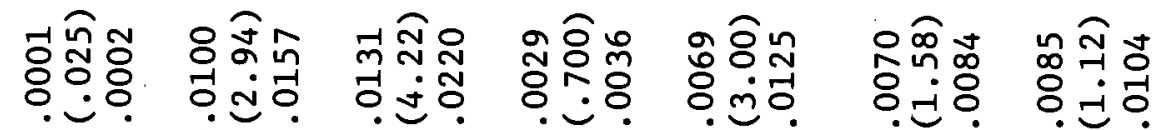

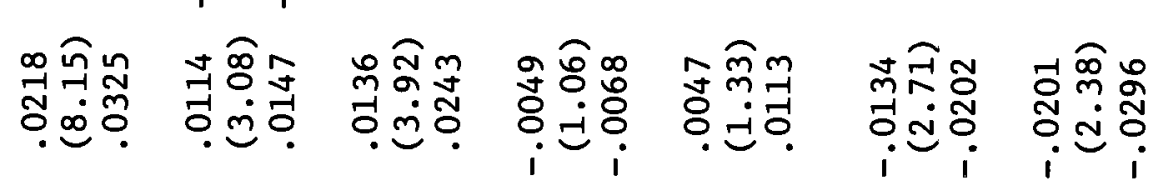

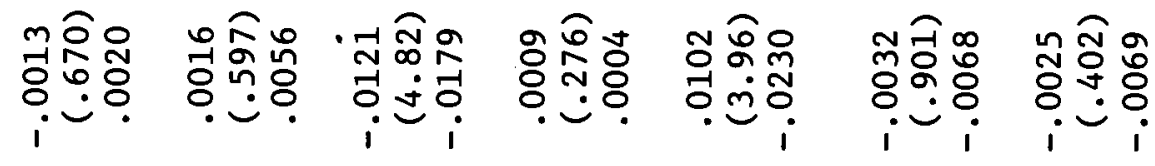

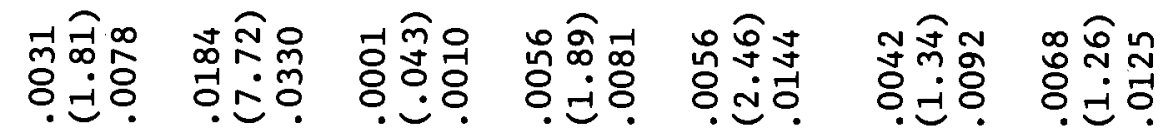

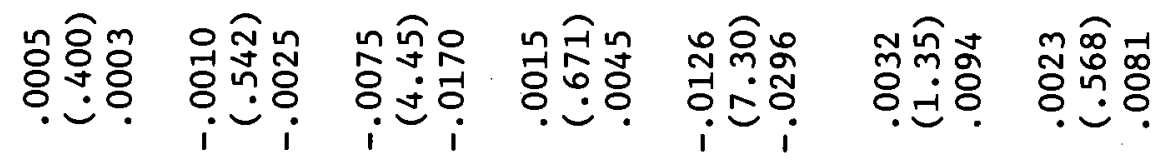

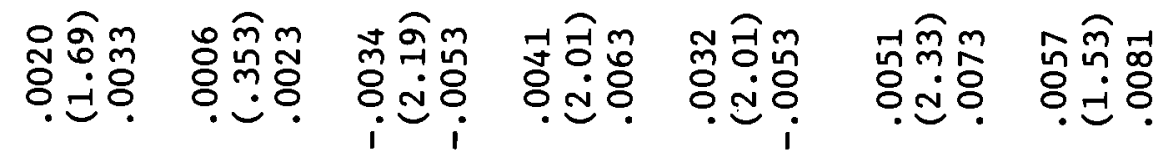

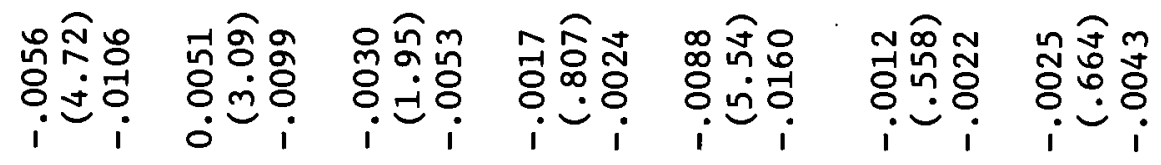

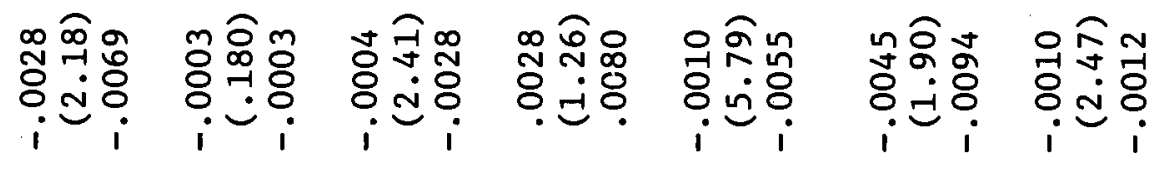

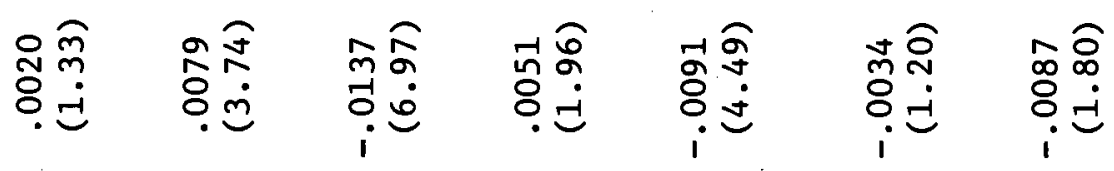

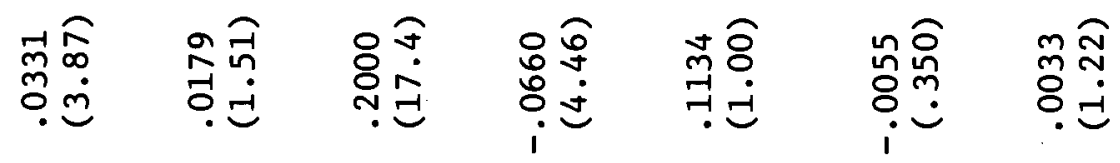

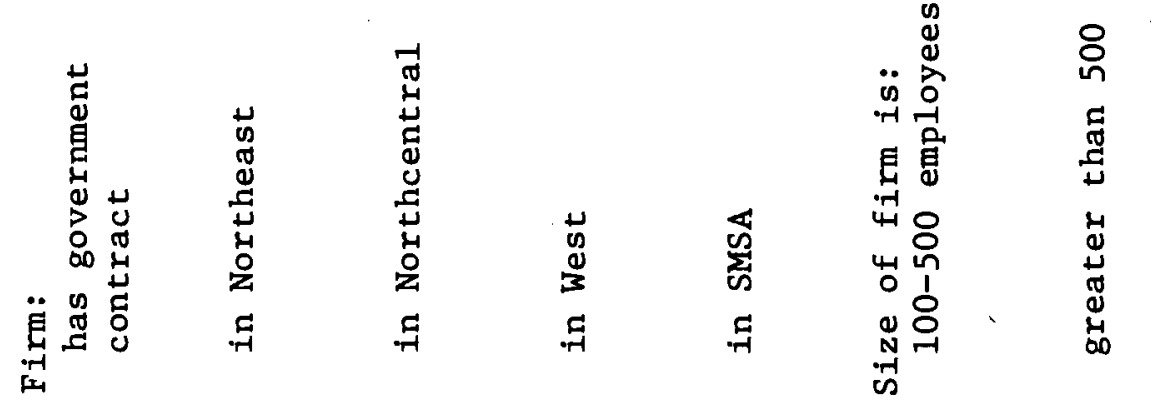




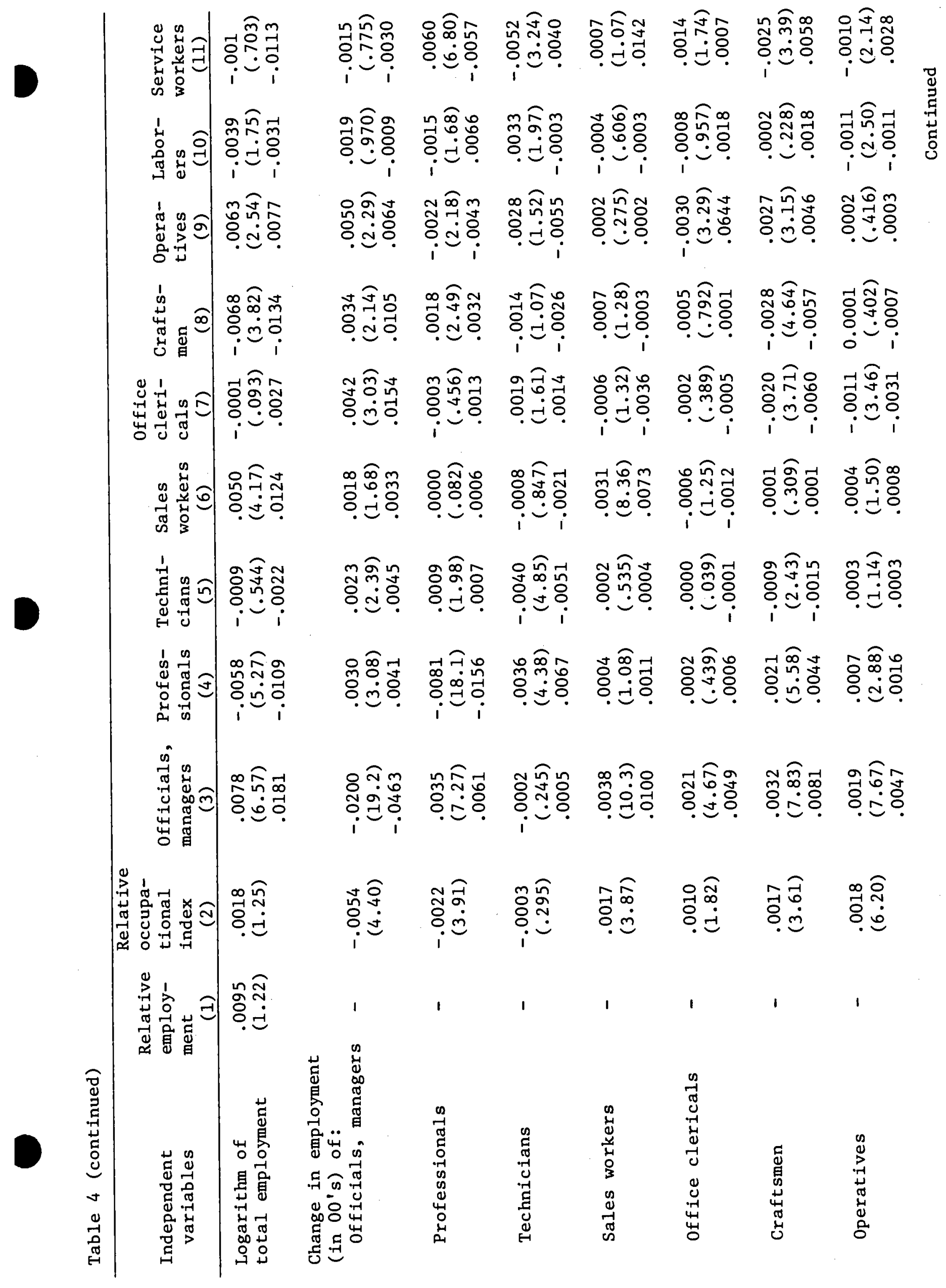




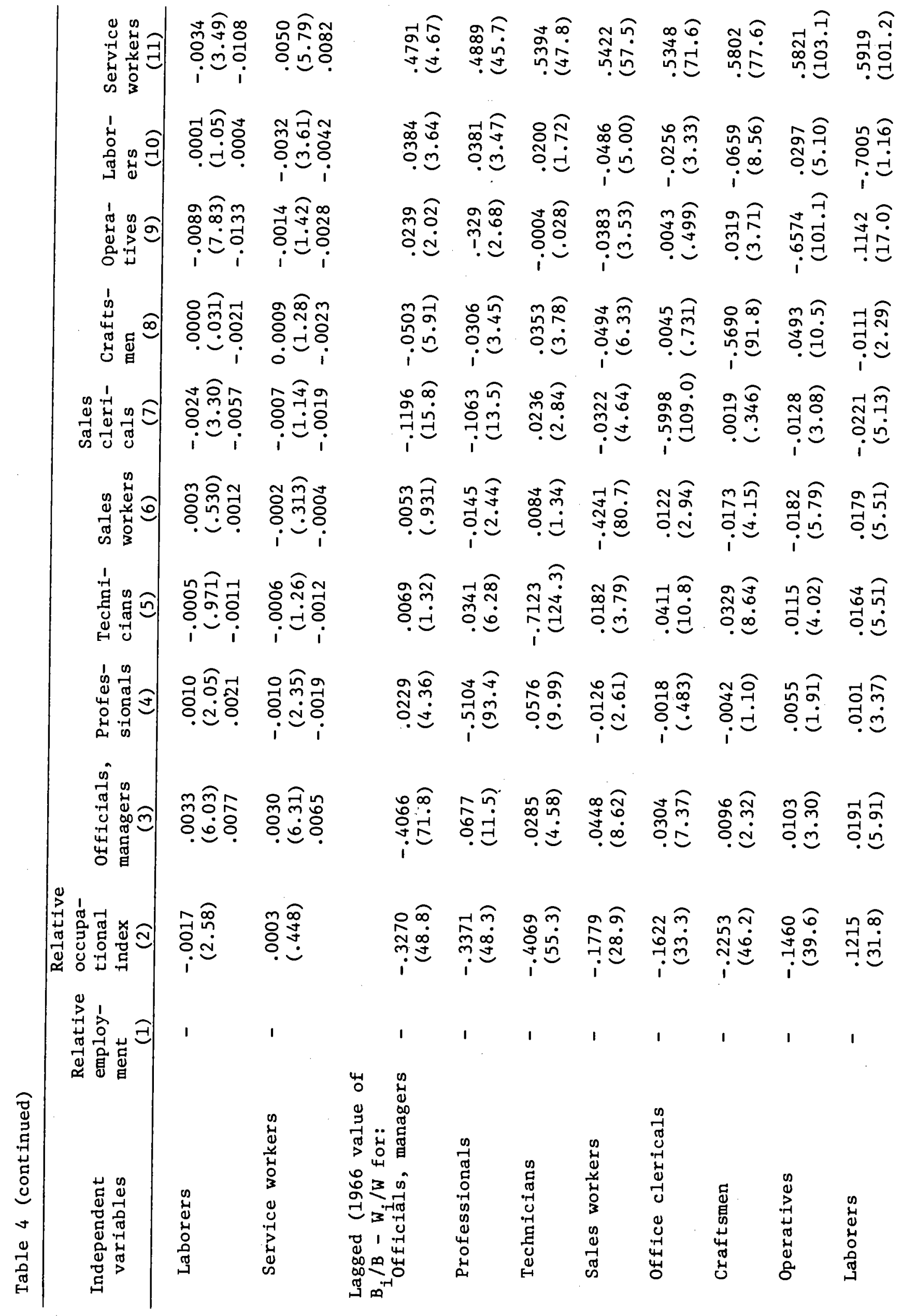



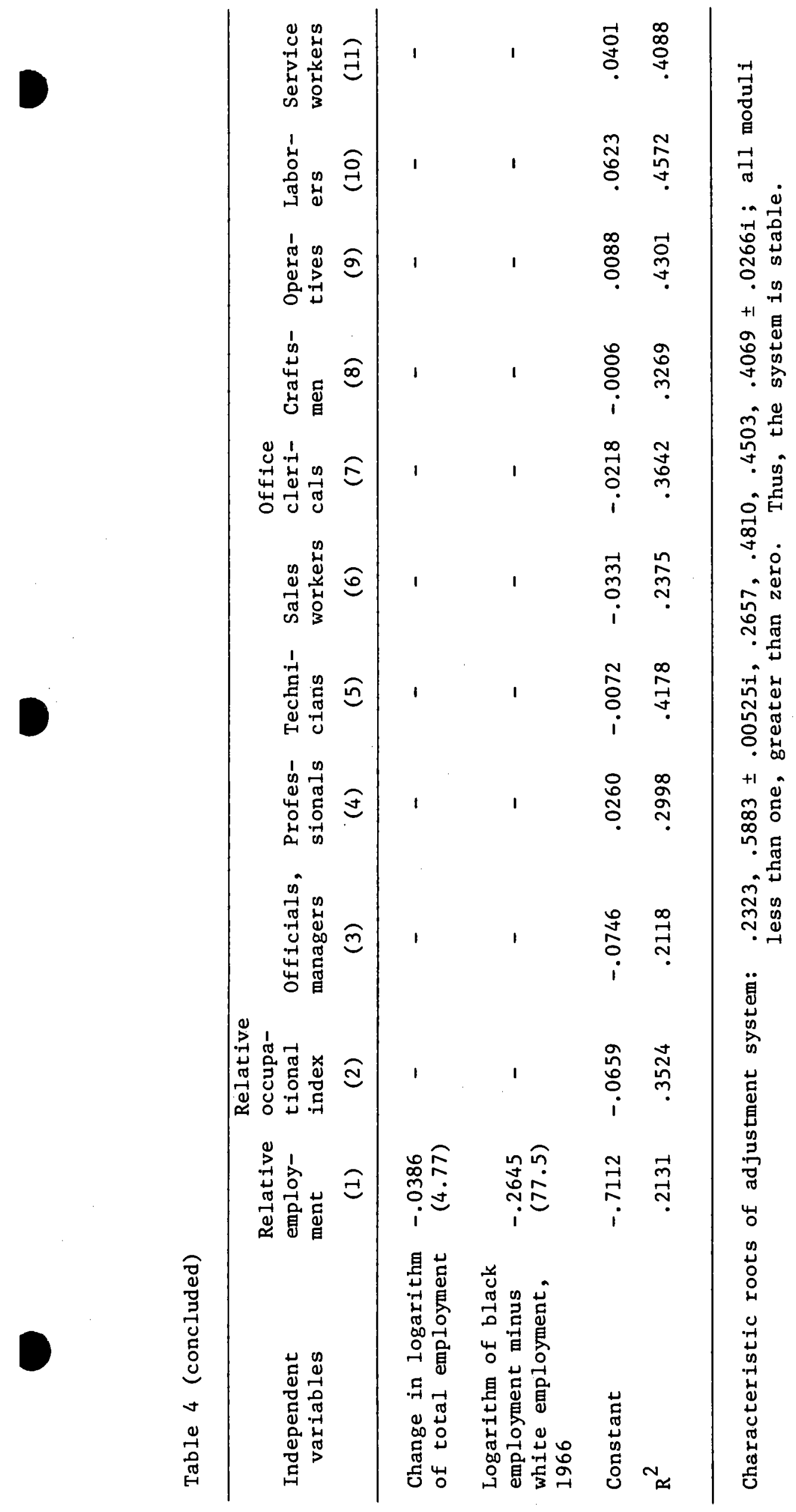
Table 5. Estimates of the percent effect of the presence of a government contract on the change in the employment and occupational distribution of black male workers relative to white male workers, 1966-70.

\begin{tabular}{|c|c|c|c|}
\hline Line no. & Occupation & $\begin{array}{l}\text { Estimated short-run } \\
\text { coefficient ( } t \text {-value) }\end{array}$ & $\begin{array}{l}\text { Estimated long-run } \\
\text { coefficient }\end{array}$ \\
\hline 1 & Total employment & $\begin{array}{r}3.307 \\
(2.84)\end{array}$ & 12.89 \\
\hline 2 & Officials and managers & $\begin{array}{r}-.279 \\
(-2.18)\end{array}$ & -.693 \\
\hline 3 & Professionals & $\begin{array}{r}-.560 \\
(-4.71)\end{array}$ & -1.061 \\
\hline 4 & Technicians & $\begin{array}{r}.199 \\
(1.68)\end{array}$ & .331 \\
\hline 5 & Salesmen & $\begin{array}{l}.052 \\
(.40)\end{array}$ & .028 \\
\hline 6 & Clerical workers & $\begin{array}{r}.304 \\
(1.80)\end{array}$ & .785 \\
\hline 7 & Craftsmen & $\begin{array}{l}-.129 \\
(-.67)\end{array}$ & 196 \\
\hline 8 & Operatives & $\begin{array}{c}2.18 \\
(8.15)\end{array}$ & 3.25 \\
\hline 9 & Laborers & $\begin{array}{l}.006 \\
(.025)\end{array}$ & .170 \\
\hline 10 & Service workers & $\begin{array}{l}-1.77 \\
(-7.65)\end{array}$ & -2.86 \\
\hline
\end{tabular}


workers over white workers in firms with government contracts reflected in line 1 was distributed by occupation. As can be seen from the table, the largest positive difference between those firms with and without government contracts fell in the operative category. To offset this positive difference, the change in the relative percentage of black workers in the service worker category was smaller among government contractors. The other positive coefficients in the table are for technicians, clerical workers, salesmen, and laborers, although the former are marginally insignificant statistically and the latter are essentially zero. The other negative coefficients in the table are for the managerial, professional, and craft occupations, although only the former two are statistically significant. Except for a reversal of sign in the case of craftsmen, the long-run effects preserve the same pattern as the short-run effects, but are algebraically larger. In sum, the basic results of Table 5 indicate that the presence of a government contract in a firm was associated with a statistically significant and larger increase in the employment of black workers relative to white workers than was the case in the firms without government contracts. The increase in the relative employment of black workers increased their representation compared to white workers primarily in the operative occupation, and decreased their relative representation primarily in the service and professional occupations.

Table 6 summarizes the estimated overall quantitative impact of the pressure of governmental efforts to increase the portion of black male workers relative to white male workers. According to these results, in the short run the governmental effort increased the employment of 
Table 6. Estimated partial effect on relative wage bill.

\begin{tabular}{|c|c|c|c|}
\hline Line no. & Occupation & $\begin{array}{l}\text { Estimated short-run } \\
\text { coefficient }\end{array}$ & $\begin{array}{l}\text { Estimated long-run } \\
\text { coefficient }\end{array}$ \\
\hline 1 & Total employment & 1.654 & 6.424 \\
\hline 2 & Officials and managers & -.264 & -.659 \\
\hline 3 & Professionals & -.529 & -1.002 \\
\hline 4 & Technicians & .188 & .312 \\
\hline 5 & Salesmen & .042 & .0238 \\
\hline 6 & Clerical workers & .238 & .614 \\
\hline 7 & Craftsmen & -.107 & -.163 \\
\hline 8 & Operatives & 1.59 & 2.37 \\
\hline 9 & Laborers & .003 & .009 \\
\hline 10 & Service workers & -1.059 & -1.710 \\
\hline \multicolumn{2}{|c|}{ Total employment effect } & 1.65 & 6.42 \\
\hline \multicolumn{2}{|c|}{$\begin{array}{l}\text { Total occupational distribution } \\
\text { effect }\end{array}$} & .100 & -.21 \\
\hline \multicolumn{2}{|c|}{ Total wage share } & 1.75 & 6.21 \\
\hline
\end{tabular}


black workers relative to white workers by 1.7 percent while in the long run the increase is 6.4 percent. In contractor firms, the occupational position of black workers relative to white workers increased by .1 percent while it is expected to decrease by .2 percent in the long run. Thus, the governmental effort increased the wage share by 1.8 percent over the 1966 to 1970 period, while this increase is expected to rise to 6.4 percent in the long run.

It is possible to briefly summarize the effects of the other variables we examined on the employment and occupational position of black male workers relative to white male workers. The sets of variables we examined were a set of regional dummy variables, a variable equal to unity if the firm was located inside a Standard Metropolitan Statistical Area, a set of variables representing the size in total employment (in 1970) of the firm, a set of variables representing the change in total male employment in each of the nine occupational categories, and the 1966 (lagged) relative position of black workers in the firm. We first describe the estimated effects of these variables on the employment of black male workers relative to white male workers and then the estimated effects of these variables on the relative occupational position of black workers. As we have observed previously, the sum of these two effects is the estimated effect of the variable on the relative share of black wages.

Region appears to be the most important factor assoclated with relative employment increases for black workers. In particular, the relative employment of black workers increased by 20 percent more in the North Central region of the U.S. than in the South, and by about 
18 and 26 percent more than in the Northeast or West. Second, there is no indication that black relative employment changes were significantly related to size of firm. Third, the rate of growth of employment of the firm was negatively related to changes in the relative employment of black workers, although the size of this effect was very small. Finally, the growth over 1966 to 1970 in the relative employment of black workers was smaller in firms where the 1966 ratio of black to white employment was highest.

Just as region of location was an important determinant of the change in the relative employment of black workers, it was also an important determinant of the change in the relative occupational position of black workers. In particular, the relative occupational position of black workers increased by 1.4 percent less in the North Central region than in the South, and by 2.2 and 1.9 percent less than in the Northeast or West. This suggests that the relative employment increases of black workers in the North Central region were a result of the migration of black workers from the South. If these migrants were from the lower paying occupational categories in the South, then their migration would by definition increase the relative occupational distribution of black workers in the South and decrease their average relative position in the North Central region so long as the in-migrants were in lower paying occupations than the workers already in the North Central region. Second, the relative occupational position of black workers increased significantly less in firms inside of SMSA's than in firms outside SMSA's. Third, there was little relationship between firm size and changes in the relative occupational position of black 
workers. Fourth, the change in the relative occupational position of black workers was greater the greater the growth of employment in the middle level occupations, i.e., sales, clerical, craft, and operative workers. On the other hand, the growth in the relative occupational position of black workers was smaller the greater was the growth in employment of workers in the highest or lowest paying occupations, i.e., professionals, managers, or laborers. Finally, the increase in the relative occupational position of black workers was smaller the greater the relative occupational position of black workers in the firm in 1966.

\section{b. Integration Effects}

The analysis to this point has been performed for only those firms that contained at least one black and one white employee in both 1966 and 1970. Since black workers make up only one-eighth of the population, many firms would not be expected to be "integrated" in this sense. In fact, of the 40,445 firms in the sample, on 1 y 24,535 contained at least one black and one white male worker. It is of some interest, therefore, to know what effect the overall government effort to increase the relative position of black workers has had on these firms. In order to examine this question we have estimated linear probability functions using data for those firms that had no black male worker in 1966 and in which the dependent variable equals unity if the firm contained at least one male black worker in 1970, and is zero otherwise. Table 7 reports the results of this analysis for total establishment integration as well as detailed 
ด้

ดู ฏ

.

n

裁

少

3 虫

艺艺

के

옹

兵年

舁

4 0

㟧

点

त)

山

$+10$

包

ค 논

노욜

م. 品

๑今。

山.

용

त्त बे

忒口貣

峞 $\mathrm{H}$.

岕岕

ต

吕 1

至 정

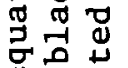

\&

동 웅 웅

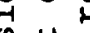

品

(1)

品先

$\dot{4} \stackrel{0}{0}$

ఫี

需

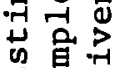

玟昌

$\stackrel{\substack{\infty \\-1}}{n}$

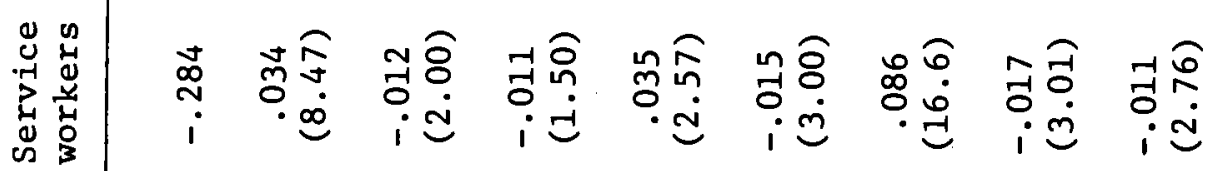

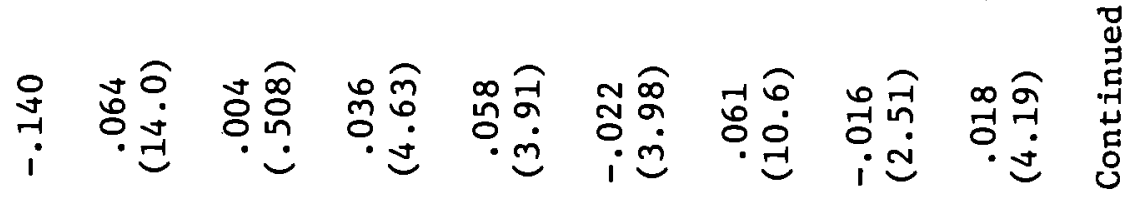

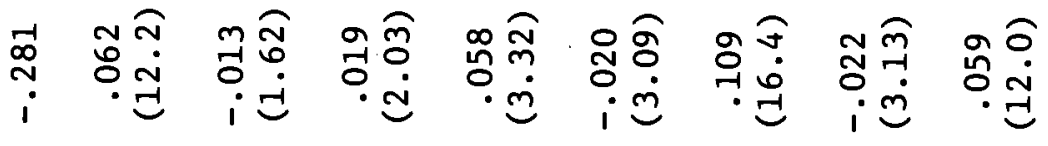

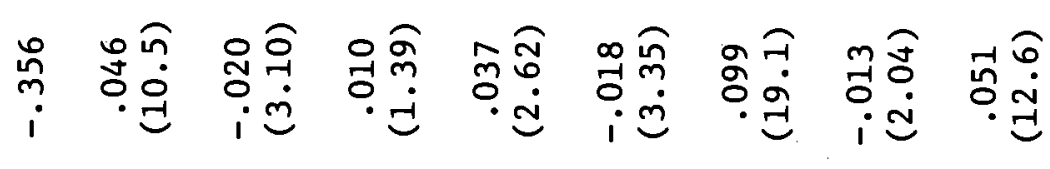

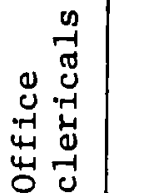

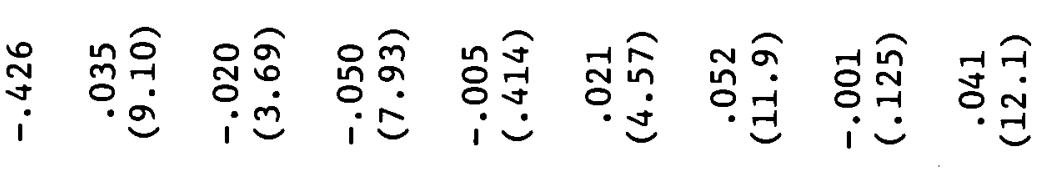

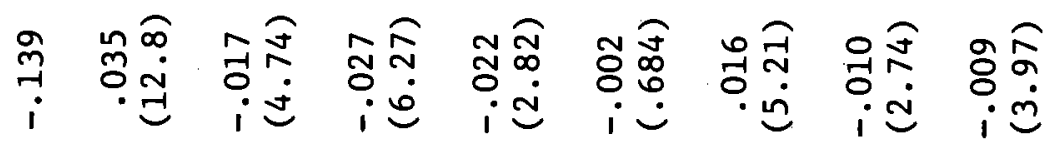

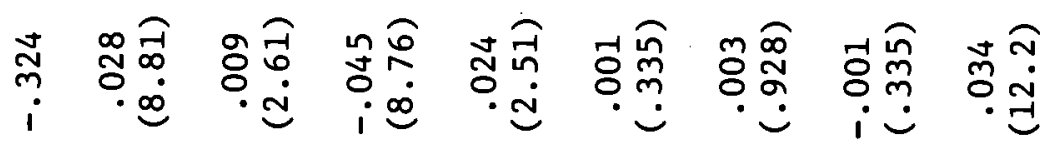

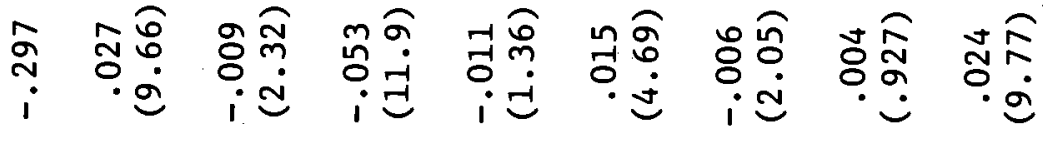

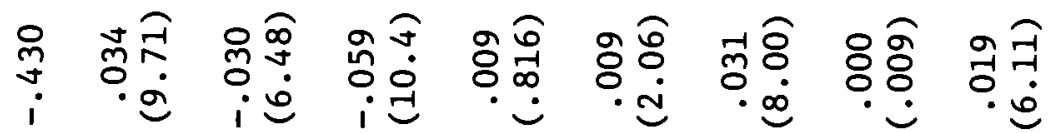

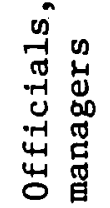

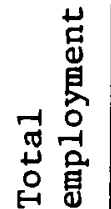

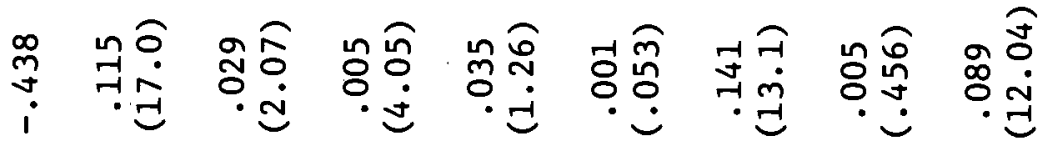

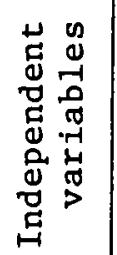

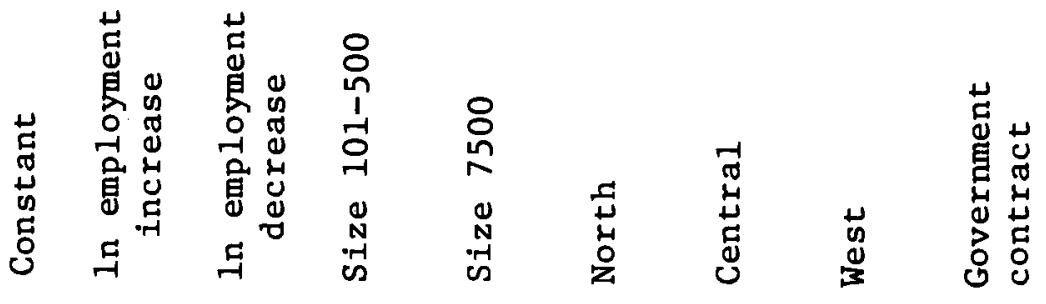



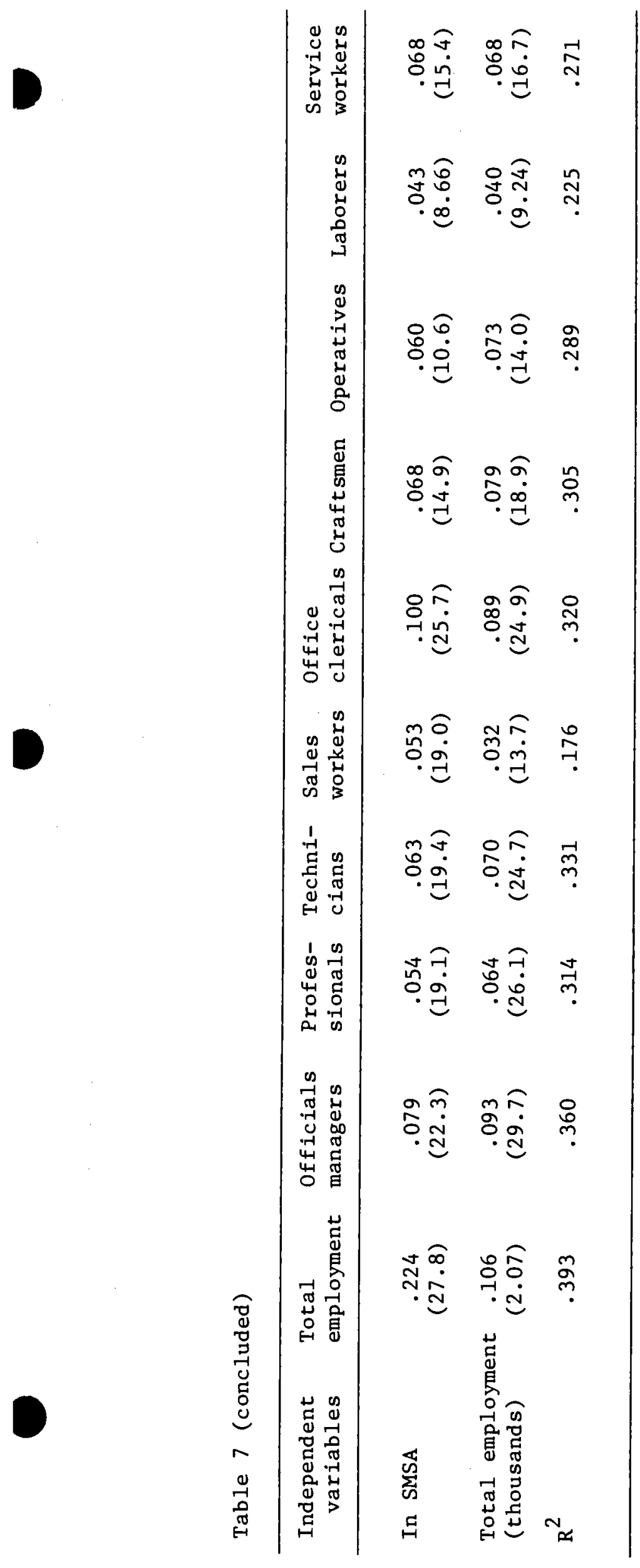
occupational integration. Since the linear probability model is known to suffer from important statistical limitations, we computed estimates of these equations using the logit model on a subsample of firms. These results, reported in Appendix C, demonstrate that if the true integration probability process is governed by a logistic disturbance, the linear probability model provides a reliable guide to the true effects of a government program.

Table 8 lists the estimated effect of the presence of a government contract on the probability that a firm that was not integrated in 1966 was integrated in 1970. Integration may be defined for the firm as a whole, and this result is reported in line 1 of the table, or for each of the separate occupations, and these results are reported in 1ines 2-10. As can be seen from the table, the probability was .09 larger that a firm that was not integrated in 1966 would be integrated In 1970 if the firm had a government contract. The results for the separate occupations are similar, and in all cases statistically significant. These results imply that the presence of the overall government effort significantly increased the extent of integration in American industry. Even if the increase in the employment of black workers is relatively small in each firm so affected, there is a substantial number of firms involved so that this effect may not appear so small when taken in the aggregate. 
Table 8. Estimated effects of the presence of a government contract on the probability that a firm with no black male worker in 1966 employed at least one black male worker in 1970.

\begin{tabular}{|c|c|c|}
\hline Line no. & Occupation & Estimated coefficient ( $t$-value) \\
\hline 1 & Total employment & $\begin{array}{c}.089 \\
(12.0)\end{array}$ \\
\hline 2 & Officials and managers & $\begin{array}{c}.019 \\
(6.11)\end{array}$ \\
\hline 3 & Professionals & $\begin{array}{c}.024 \\
(9.77)\end{array}$ \\
\hline 4 & Technicians & $\begin{array}{c}.034 \\
(12.2)\end{array}$ \\
\hline 5 & Sales workers & $\begin{array}{l}-.009 \\
(3.97)\end{array}$ \\
\hline 6 & Clerical workers & $\begin{array}{c}.041 \\
(12.1)\end{array}$ \\
\hline 7 & Craftsmen & $\begin{array}{c}.051 \\
(12.6)\end{array}$ \\
\hline 8 & Operatives & $\begin{array}{c}.059 \\
(12.0)\end{array}$ \\
\hline 9 & Laborers & $\begin{array}{c}.018 \\
(4.19)\end{array}$ \\
\hline 10 & Service workers & $\begin{array}{l}-.011 \\
(2.76)\end{array}$ \\
\hline
\end{tabular}


$\underline{\text { Summary }}$

We have used detailed records from the Equal Employment Opportunity tapes for a matched sample of firms in 1966 and 1970 to estimate the extent to which the change in the position of black male workers relative to white male workers was greater among firms with contracts with the Federal government than among firms without such contracts. Since all of the Office of Federal Contract Compliance efforts to improve the relative position of black workers operate on firms with Federal contracts, and since the EEOC's efforts are presumably more successful with such firms, we concentrate on this issue because it presumably gives us some indication of the overall impact of government efforts on changes in the relative position of black workers.

First, we find that the relative employment of black male workers increased by 3.3 percent more over the period 1966 to 1970 in firms with government contracts than in firms without government contracts, and that this difference is statistically significant. The long-run effect is estimated to be 12.9 percent. Second, we find that in the short run the relative occupational position of black male workers increased by .2 percent more in firms with government contracts than in firms without contracts, but that this difference is not statistically significant. In the long run, a .4 percent decrease is expected.

The most important factor affecting the change in the relative position of black male workers in these data appears to be the migration of black workers to the North Central region of the U.S. The employment of black workers relative to white workers increased by approximately 
20 percent more in the North Central region than in any other region of the country. This migration also resulted in a smaller rate of increase in the relative occupational position of black male workers in the North Central region than in any other region, and undoubtedly resulted because the migration of workers was from the lowest paying occupational categories. This presumably increased the growth in the relative occupational position of black male workers outside the North Central region and decreased this growth inside that region.

Finally, we have investigated the factors that affected the probability that a firm with no black male worker in 1966 would have hired at least one such worker by 1970 . We find that the probability that a firm that was not "integrated" in this sense in 1966 was integrated in 1970 was nearly .1 percent higher in 1970 among firms with government contracts than in firms without them. 
APPENDIX A

Using the notation of Section I.a, in the text,

$i^{\prime}\left(o_{t}-o_{t-1}\right)=0=I^{\prime} \Lambda \beta \bar{x}+i^{\prime} \Lambda \Gamma d-i^{\prime} \Lambda o_{t-1}+i^{\prime} \varepsilon_{t}$

where 1 is a $J \times 1$ vector with unit elements. Thus, for general $\bar{x}, d$, $0_{t-1}$,

$$
\begin{aligned}
& i^{\prime} \Lambda \beta=0 \\
& i^{\prime} \Lambda \Gamma=0
\end{aligned}
$$

and

$$
1^{\prime} \Lambda=0
$$

This implies that knowledge of the coefficients of any $\mathrm{J}-1$ equations automatically gives the coefficients of the omitted equation. Note further that since

$$
I^{\prime} 0_{t-1}=0
$$

we may replace the regressors $0_{t-1}$ with $o_{t-1}^{\Delta}$, a $J-1 \times 1$ vector. For convenience suppose the final element of the vector, $\left(0_{t-1, J}\right)$, is removed. The choice of the element to be removed is inessential. Letting $i^{\Delta}$ be a $J-1 \times 1$ vector of unit elements, $\left(i^{\Delta}\right)^{\prime} 0_{t-1}^{\Delta}=-0,-1, J^{*}$ Rewriting the original equation, we see that

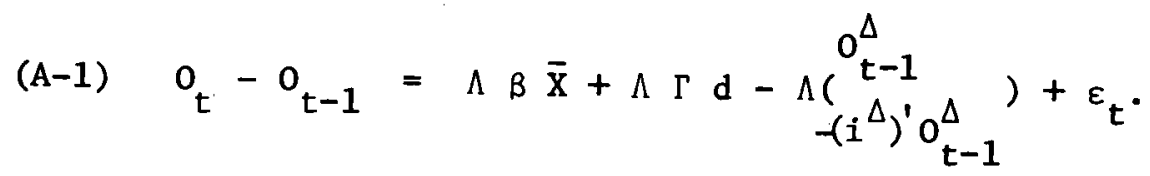


Partition $\Lambda$ into $[\tilde{\Lambda} \tilde{C}]$ where $\tilde{\Lambda}$ is a J x J-1 matrix of coefficients and $\tilde{C}$ is a column vector. The new equation system is equivalent to

$$
\text { (A-2) } \begin{aligned}
o_{t}-o_{t-1} & =\Lambda B \overline{\mathrm{x}}+\Lambda \Gamma \mathrm{d}-\tilde{\Lambda} o_{t-1}^{\Delta}+\tilde{\mathrm{C}} i^{\prime} o_{t-1}^{\Delta}+\varepsilon_{t} \\
& =\Lambda \beta \overline{\mathrm{x}}+\Lambda \Gamma \mathrm{d}-\left[\tilde{\Lambda}-\tilde{\mathrm{C}} i^{\prime}\right] 0_{t-1}^{\Delta}+\varepsilon_{t} .
\end{aligned}
$$

Note further that in long-run equilibrium $\left(0_{t}=0_{\infty}\right)$ the expected value of long-run values is

$$
O_{\infty}=\beta \bar{X}+\Gamma d
$$

Since $i^{\prime} O_{\infty}=0$, it is clear that

$$
(\mathrm{A}-3) \quad i^{\prime} \beta=0 \quad \text { and } \quad i^{\prime} \Gamma=0 \text {, }
$$

where is is a $\mathrm{J} \times 1$ unity vector. This implies that we may use precisely the same reasoning as in the previous paragraph to write

$$
\begin{aligned}
& \Lambda \beta=\left[\tilde{\Lambda}-\tilde{\mathrm{C}} \dot{i}^{\prime}\right] \beta^{\Delta} \\
& \Lambda \Gamma=\left[\tilde{\Lambda}-\tilde{\mathrm{C}} \dot{i}^{\prime}\right] \Gamma^{\Delta}
\end{aligned}
$$

where " $\beta$ " is " $\beta$ " with the last row removed, and " $\Gamma$ " is " $\Gamma$ " with its final element removed. 
Drop the final equation and make the appropriate change in $\left[\tilde{\Lambda}-\tilde{C}_{i}^{\prime}\right]$ (i.e., delete its final row) to reach

$$
\left[\Lambda^{\Delta}-\left(C^{\Delta}\right) i^{\Delta^{\prime}}\right]
$$

where $\Lambda^{\Delta}$ is a J-1 $\times$ J-1 matrix, and $C^{\Delta}$ is the final column of $\Lambda$ with its last element deleted, and $i^{\Delta}$ is a $(J-1) \times 1$ vector of unity elements. The reduced equation system is

$$
\text { (A-4) } \begin{aligned}
0_{t}^{\Delta}-0_{t-1}^{\Delta}= & {\left[\Lambda^{\Delta}-\left(C^{\Delta}\right)\left(i^{\Delta}\right)^{\prime}\right] \beta^{\Delta} \bar{x}+\left[\Lambda^{\Delta}-\left(C^{\Delta}\right)\left(i^{\Delta}\right)^{\prime}\right] \Gamma^{\Delta} } \\
& -\left[\Lambda^{\Delta}-C^{\Delta}\left(i^{\Delta}\right)^{\prime}\right] 0_{t-1}^{\Delta}+\varepsilon_{t}^{\Delta}
\end{aligned}
$$

where $0_{t}^{\Delta}, 0_{t-1}^{\Delta}$, and $\varepsilon_{t}^{\Delta}$ are the original vectors with the final element removed.

In general, the matrix in brackets is nonsingular, and estimable. Accordingly, we can estimate $\beta^{\Delta}$ and $\Gamma^{\Delta}$. Using equations $(A-3)$, we estimate $\beta$ and $\Gamma$. Note, however, that $\Lambda$ is not estimable without further information. Note further that while the variance-covariance matrix of the original system is singular, in the reduced system this complication is avoided. Thus we have shown that knowledge of any J-1 short-run equations is sufficient to determine both short-run and long-run coefficients for the control variables and the government contract variable. Stability of the reduced system of equations implies stability of the original system. Since the characteristic roots of the adjustment matrix presented in Table 4 are all less than one in modulus, the complete system is stable. 


\section{APPENDIX B}

The previous appendix shows that estimates of $\Lambda$, the adjustment matrix, are not needed to estimate long-run coeeficients. Nonetheless, if estimates are available, they provide an additional check on the mode1. Implausibly low rates of adjustment, or implausible orderings or rates of adjustment will cast doubt on our estimates. Specificity of training, and length of the training period should cause slower rates of adjustment in the more skilled occupations. Without further information, it is impossible to estimate $\Lambda$. One restriction, overly strong, that will provide identification is the assumption of symmetry for $\Lambda$. A weaker restriction, consistent with symmetry, is the assumption that

$(\mathrm{A}-5) \quad \Lambda i=0$,

where $i$ is a $J \times 1$ vector of ones, with $J$ being the number of occupations. Since we know that the dependent variable in the $\mathrm{J}$ equations must be zero,

(A-6) $\quad i^{\prime} \Lambda=0$.

It is easy to verify that if $\Lambda$ is symmetric, and the last equation applies, then the previous equation applies as well. It is also easy to verify that restriction (A-5) allows estimation of $\Lambda$ from $\left[\tilde{\Lambda}-\tilde{C} i^{\prime}\right]$. 
The empirical results are presented in Table A-1. Reading down the rows for a given column gives the coefficient on the lagged difference in proportion for the dependent variable designated in the row. Casual inspection of the table shows that the matrix is remarkably "close" to symmetry despite the fact that symmetry is not an implication of assumption (A-5). Letting $\lambda_{i j}$ be the element of $\Lambda$ in the $i$ th row and $j$ th column, one index of the departure of the matrix from full symmetry is

$\sqrt{\frac{1}{N} \sum_{\substack{i \neq j \\ i \neq j}}\left(\lambda_{i j}-\lambda_{j i}\right)^{2}}$

where $\mathrm{N}$ is the number of distinct off diagonal elements in the $\Lambda$ matrix if $\Lambda$ is symmetric. The value of the index is .0342 which indicates a sma11 average deviation from symmetry.

Reading down the diagonal, the own adjustment coefficient tends to increase as the skill level decreases, suggesting that adjustments to final equilibrium are slower for more highly skilled occupations. This result is consistent with prior notions on the adjustment rates of fixed factors. Nonetheless, the implied rates of adjustment seem slow, especially when a four year time period separates the dependent variable and its lagged value. First order serial correlation in the disturbances of equations (15) will tend to depress the estimated rates of adjustment. Moreover, serial correlation will tend to impart symmetry in the estimated $\Lambda$ matrix. Since we have only two points in time, we cannot test for serial correlation in a distributed lag model. 
51

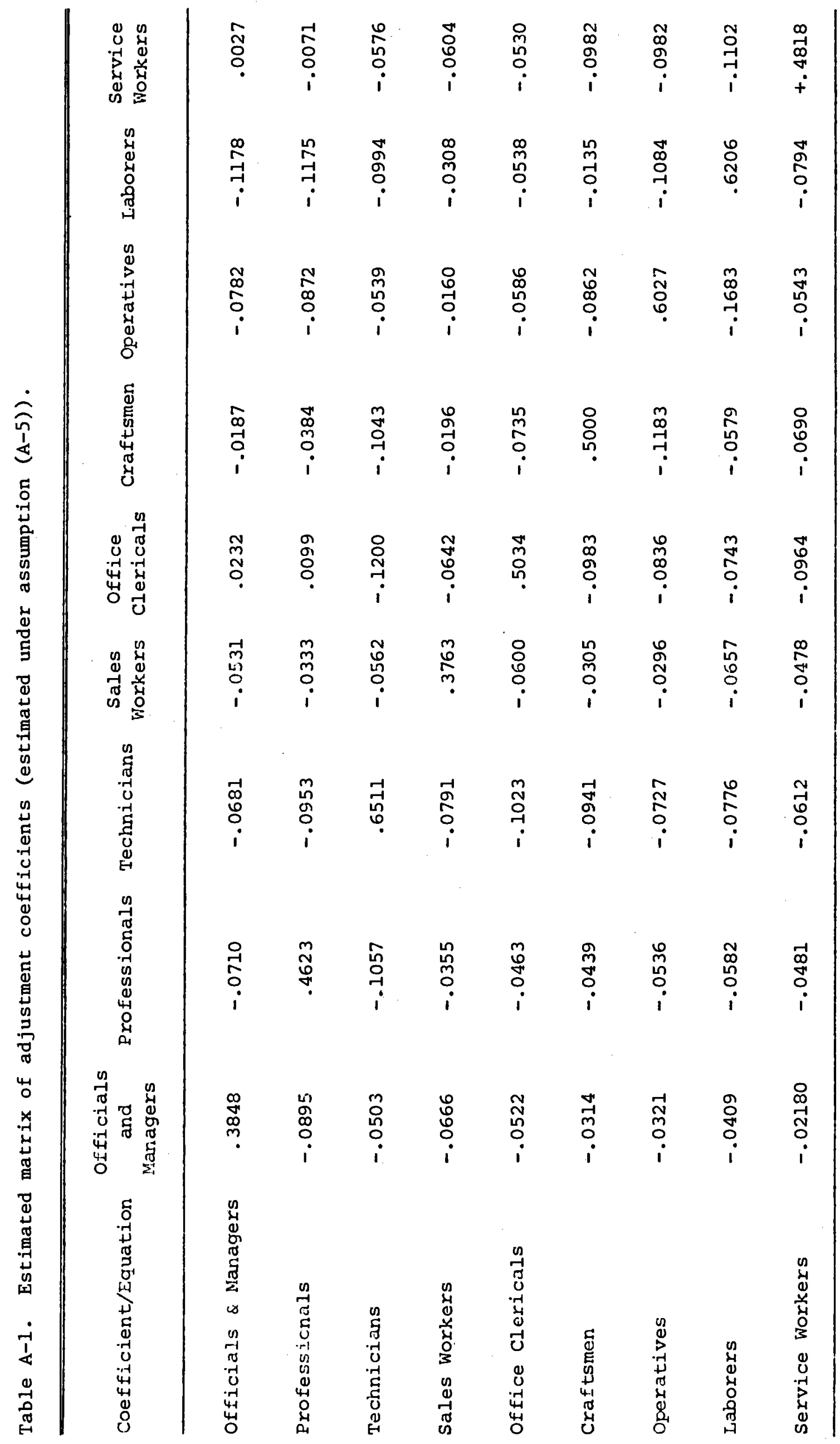


Nonetheless, we conjecture that a lag model is appropriate, although serial correlation may be present as well. It would be an unlikely coincidence to find that the ordering of own adjustment coefficients is so closely in accord with theory if serial correlation were the only factor leading to significant coefficients on the lagged variables. 


\section{APPENDIX C}

In the text, we present empirical results on the effect of contractor status on the racial integration of firms. The analysis is performed using the linear probability model which is known to suffer from important defects. 9

Accordingly, it is of interest to compare results from this conceptually defective but computationally effective method with results from a more attractive statistical model. The logistic model is known to possess a likelihood function which possesses sufficient statistics, Thus, it is possible to compute efficient and consistent estimates of the probability of integration.

Since the logistic technique is computationally more expensive, we randomly selected a 10 percent sample of the firms used to compute the results from the linear probability model. Those results are reported in Table A-2. The rows in this table correspond to the columns of Table 7 in the text.

For our purposes, the most appropriate comparison is between the coefficient on the variable "government contract" in the linear probability model, presented on line 4 within each group, and the implied probability from the logistic mode1, presented on line 3 . Both results are computed from the identical subsample of 1420 firms. The estimates from the two models are quite close, indicating that the results reported in the text may be taken as good approximations to a more theoretica11y desirable econometric model. 
Table A-2. A comparison of the logistic results with the linear probability model for a subsample of 1,420 firms selected randomly from the tape.*

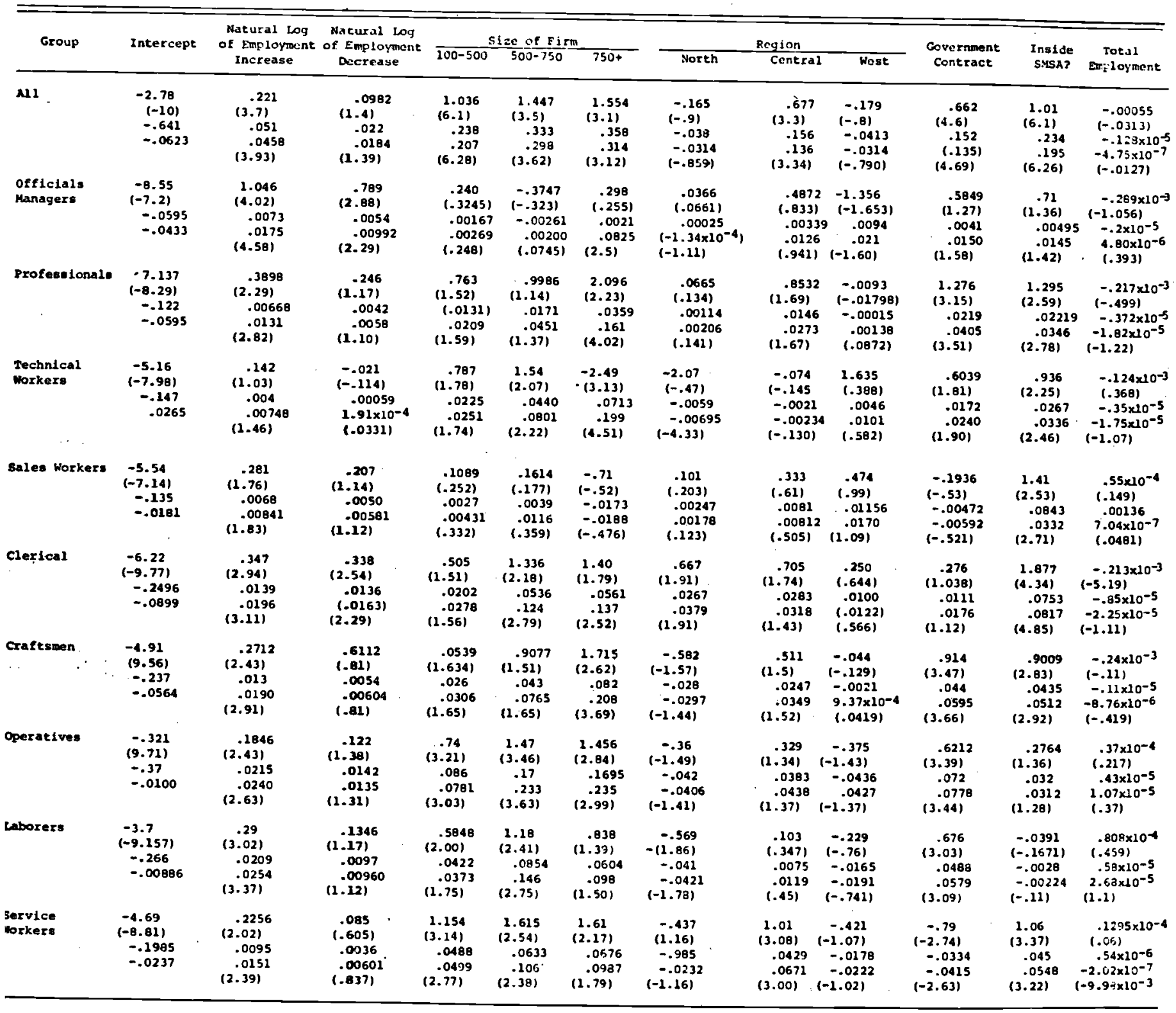

*The first line in each group records the logit coefficient, the second is the associated normal statistic, the third line records the partial derivative of the probability of integration with respect to the associated variable. This is to be compared with the coefficient of the linear probability model recorded in the fourth line. The fifth line shows the $t$ statistic for the linear probability model. 
FOOTNOTES

1. The material in the introduction draws heavily from Chapter 4 of R. P. Nathan's excellent Jobs and Civil Rights, prepared for the U.S. Commission on Civil Rights. Clearinghouse Publication No. 16, April, 1969.

2. It has been estimated that in March 1967 there were 228 fulltime professional contract compliance personnel in all government agencies except the OFCC to investigate 225,000 contractor facilities. (R. Nathan, op. cit., p. 113.)

3. Readers familiar with the work of H. G. Lewis reported in Unionism and Relative Wages, Chicago, 1963, will recognize the similarity in Lewis' methodology and our own.

4. See M. Nadiri and S. Rosen, Interrelated Factor Demand, National Bureau of Economic Research, New York, 1974.

5. Adiscussion of this point is given in Appendix A. With a fairly mild assumption, it is possible to estimate $\Lambda$ as we11. This provides a further check on the mode1. These results are reported in Appendix $B$.

6. This would also be a desirable project to undertake for the entire universe of firms, since it has been estimated that perhaps only three-fourths of the firms obligated to submit an EEO-1 form actually do so. A periodic audit of a random sample of firms whose EEO-1 forms have not been tabulated would produce estimates of the causes for non-response in the overall universe of obligated firms and might have the additional benefit of producing a higher response rate in the longer run. 
7. We are thus treating the results in Table 3 as a linear probability function. There are well known statistical problems that arise from using this procedure. As is also well known, the same computational results may be interpreted as a linear discriminant function. Under this interpretation a simple transformation of the coefficients in Table 3 would make them the weights in a function that would allow us to predict which of two populations an item had come from, the matched or unmatched groups. In some ways the linear discriminant function would be a better way to interpret the computations in Table 3 for the problem we are examining here.

8. This information appears in a letter dated December 5, 1973, from George Travers, Associate Director for Plans, Policies and Programs, Employment Standards Administration, Office of Federal Contract Compliance, U.S. Department of Labor, to Orley Ashenfelter. Travers estimates that in 1971, 28 percent of government contractors were listed as noncontractors. Since similar data procedures were employed in 1966 and 1970, as in 1971, it is likely that this estimate applies to our data as well.

9. See, e.g., A. S. Goldberger, Econometric Theory, Wiley, 1964. 